\title{
Breastfeeding During Early Infancy is Associated with Higher Weight- Based World Health Organization Anthropometry
}

\author{
Daniel H. Libraty ${ }^{*}$, , Rosario Z. Capeding ${ }^{2,3}$, AnaMae Obcena ${ }^{2}$, Job D. Brion ${ }^{4}$ and Veronica Tallo ${ }^{5}$ \\ ${ }^{I}$ Division of Infectious Disease and Immunology, Department of Medicine, University of Massachusetts Medical School, \\ Worcester, MA, USA \\ ${ }^{2}$ Department of Medicine, Research Institute for Tropical Medicine, Manila, Philippines \\ ${ }^{3}$ Department of Microbiology, Research Institute for Tropical Medicine, Manila, Philippines \\ ${ }^{4}$ San Pablo City Health Office, San Pablo, Philippines \\ ${ }^{5}$ Department of Epidemiology, Research Institute for Tropical Medicine, Manila, Philippines
}

\begin{abstract}
The World Health Organization (WHO) Expert Committee on Physical Status: The Use and Interpretation of Anthropometry established reference anthropometric standards for the growth of healthy infants and children. As part of a prospective clinical study of dengue virus infections in infants, we measured the length and weight of healthy infants in San Pablo, Laguna, Philippines at two scheduled study visits. We examined the correlation between breastfeeding and WHO anthropometric z scores during early infancy in San Pablo, Laguna, Philippines. We found that breastfeeding status and the frequency of breastfeeding during early infancy positively correlated with weight-based WHO anthropometric $\mathrm{z}$ scores.
\end{abstract}

Keywords: Breastfeeding, infant, anthropometry, weight, nutrition, bottle-feeding.

\section{INTRODUCTION}

The World Health Organization (WHO) Expert Committee on Physical Status: The Use and Interpretation of Anthropometry established reference anthropometric standards for the growth of healthy infants and children [1]. These standards were designed to reflect the growth of healthy infants and children worldwide, in both developed and developing countries. We examined the correlation between breastfeeding and WHO anthropometric z scores during early infancy in San Pablo, Laguna, Philippines. We found that breastfeeding status and the frequency of breastfeeding during early infancy positively correlated with weight-based WHO anthropometric z scores.

\section{METHODS}

Infant Clinical Study. The infant clinical study was approved by the institutional review boards of the Research Institute for Tropical Medicine, Philippines, and the University of Massachusetts Medical School. Mothers and their healthy infants were recruited and enrolled after providing written informed consent. Study enrollment began in October 2006 in San Pablo, Philippines. Healthy infants and their mothers were enrolled when the infant was between 6-18 weeks old. Additional details about the study protocol have been previously reported [2].

*Address correspondence to this author at the Rm S6-862, Division of ID, UMMS, 55 Lake Ave N, Worcester, MA 01655, USA; Tel: 508-856- 4182; Fax: 508-856-4890; E-mail: daniel.libraty@umassmed.edu
Anthropometry. At scheduled study visits, infant weight was measured to the nearest tenth of a kilogram. Infant length was measured to the nearest centimeter. WHO lengthfor-age, body mass index (BMI)-for-age, weight-for-age, and weight-for-length $\mathrm{z}$ scores for study infants were determined using the SPSS macro provided by WHO [3]. Infants with missing values or biologically implausible anthropometric $\mathrm{z}$ scores were excluded from analyses. Biologically implausible $\mathrm{z}$ scores were length-for-age $\mathrm{z}$ score $<-6$ or $>6$, BMI-for-age $\mathrm{z}$ score $<-6$ or $>6$, weight-for-age $\mathrm{z}$ score $<-6$ or $>5$, or weight-for-length $\mathrm{z}$ score $<-6$ or $>6$ [3].

Statistical Analysis. The SPSS software package (version 20.0) was used for statistical analyses. Ages are shown as median [95\% confidence interval]. Spearman rank-order correlation coefficients and $95 \%$ confidence intervals were calculated. $\mathrm{P}<0.05$ was considered significant.

\section{RESULTS AND DISCUSSION}

Clinical study. As part of a prospective clinical study of dengue virus infections in infants, we measured the length and weight of healthy infants in San Pablo, Laguna, Philippines at two scheduled study visits. We then calculated WHO anthropometric indices that use these measurementslength-for-age, BMI-for-age, weight-for-age, and weight-forlength $\mathrm{z}$ scores.

Breastfeeding is associated with higher weight-based WHO anthropometric $z$ scores compared to bottle-feeding early in infancy. Breastfeeding (exclusive or supplemental) at the first study visit (ages 2.1 [2.1-2.2] mos) was associated with higher BMI-for-age, weight-for-age, and weight-for- 
Table 1. Correlations Between Breastfeeding and WHO Anthropometric z Scores During Early Infancy (Ages 2.1 [2.1-2.2] Mos, Median [95\% CI]

\begin{tabular}{|c|c|c|c|c|}
\hline & $\begin{array}{c}\text { BMI-for-Age } \\
\text { z Score }\end{array}$ & $\begin{array}{c}\text { Weight-for-Age } \\
\text { z Score }\end{array}$ & $\begin{array}{c}\text { weight-for-Length } \\
\text { z Score }\end{array}$ & $\begin{array}{c}\text { length-for-Age } \\
\text { z Score }\end{array}$ \\
\hline \hline $\begin{array}{c}\text { Spearman } r \text { values [95\% confidence interval] for breastfeeding } \\
\text { (exclusive or supplemental) } v \text { bottle-feeding (all infants) }{ }^{\mathrm{a}}, \\
\text { p-value }\end{array}$ & $\begin{array}{c}0.13[0.11-0.15], \\
\mathrm{p}<0.001 \\
(n=9,072)\end{array}$ & $\begin{array}{c}0.12[0.10-0.14], \\
\mathrm{p}<0.001 \\
(n=9,079)\end{array}$ & $\begin{array}{c}0.11[0.09-0.13], \\
\mathrm{p}<0.001 \\
(n=9,072)\end{array}$ & $\begin{array}{c}0.02[0.00-0.04], \\
\mathrm{p}=0.14 \\
(n=9,075)\end{array}$ \\
\hline $\begin{array}{c}\text { Spearman } r \text { values [95\% confidence interval] for breastfeeding } \\
\text { frequencies (among breastfed infants) } \\
\text { p-value }\end{array}$ & $\begin{array}{c}0.10[0.08-0.12], \\
\mathrm{p}<0.001\end{array}$ & $\begin{array}{c}0.07[0.05-0.09], \\
\mathrm{p}<0.001 \\
(n=7,359)\end{array}$ & $\begin{array}{c}0.09[0.07-0.11], \\
\mathrm{p}<0.001 \\
(n=7,353)\end{array}$ & $\begin{array}{c}-0.02[-0.04-0.002], \\
\mathrm{p}=0.04 \\
(n=7,355)\end{array}$ \\
\hline
\end{tabular}

${ }^{\mathrm{a}}$ Bottle-feeding (exclusive) was coded as 0, breastfeeding (exclusive or supplemental) was coded as 1.

${ }^{\mathrm{b}}$ Daily frequencies of breastfeeding (among breastfed infants) were coded as follows:

$\leq 2$ times per $24 \mathrm{~h}$ period $=0 ; \geq 3$ and $\leq 6$ times per $24 \mathrm{~h}$ period $=1 ;>6$ times per $24 \mathrm{~h}$ period $=2$.

length WHO z scores compared to bottle-feeding (Table 1). There was no significant difference in length-for-age $\mathrm{z}$ scores between breastfed and bottlefed infants at this time point. Previous studies have reported little difference in growth patterns between breastfed and bottle-fed infants through early infancy [4]. Although we saw a significant positive correlation between breastfeeding and weight-based anthropometric $\mathrm{z}$ scores, the degree of correlation was small. There were no differences in all anthropometric $\mathrm{z}$ scores between breastfed and bottle-fed infants at the later second study visit (ages 4.4 [4.3-4.4] mos, data not shown). There was a lower percentage of breastfed infants at the second study visit compared to the first $(75 \%$ breastfed infants at second study visit vs $81 \%$ breastfed infants at first study visit). This likely contributed to the absence of a significant association, as the degree of correlation between breastfeeding and weight-based anthropometric $\mathrm{z}$ scores was small at the first study visit.

A higher breastfeeding frequency during early infancy is associated with higher weight-based WHO anthropometric $z$ scores. Among breastfed infants at the first study visit, BMIfor-age, weight-for-age, and weight-for-length WHO z scores positively correlated with breastfeeding frequencies (Table 1). This positive association was not seen with lengthfor-age $\mathrm{z}$ scores at the first study visit or with all the anthropometric measures at the second study visit during infancy (ages 4.3 [4.3-4.3] mos, data not shown). The positive association seen between breastfeeding frequencies and weight-based anthropometric $\mathrm{z}$ scores during early infancy cannot establish causation. However, the data likely provide further support for the benefits of frequent breastfeeding early in infancy $[5,6]$.

\section{CONFLICT OF INTEREST}

The authors confirm that this article content has no conflict of interest.

\section{ACKNOWLEDGEMENTS}

This work was supported by National Institutes of Health grant NIH/NIAID R01 AI091820.

\section{REFERENCES}

[1] WHO Child Growth Standards based on length/height, weight and age. Acta Paediatr Suppl. 2006; 450: 76-85.

[2] Libraty DH, Acosta LP, Tallo V, et al. A prospective nested casecontrol study of Dengue in infants: rethinking and refining the antibody-dependent enhancement dengue hemorrhagic fever model. PLoS Med. 2009; 6(10): e1000171.

[3] WHO Anthro for personal computers, version 3.2.2.: Software for assessing growth and development of the world's children. 2011. Available at: http://www.who.int/childgrowth/software/en/

[4] Nommsen-Rivers LA, Dewey KG. Growth of breastfed infants. Breastfeed Med 2009; 4(1): 45-9.

[5] Vis HL, Ruchababisha M, Hennart P. Breast-feeding and the growth and development of the infant. Int J Gynaecol Obstet 1987; 25: 239-47.

[6] Fulhan J, Collier S, Duggan C. Update on pediatric nutrition: breastfeeding, infant nutrition, and growth. Curr Opin Pediatr 2003; 15(3): 323-32. 